\title{
A Memorial Tribute to Professor Constantin Corduneanu, The Outstanding Mathematician
}

https://doi.org/10.1515/msds-2020-0115

Received May 27, 2020; accepted October 3, 2020

Abstract: This paper contains the biographical sketch and reviews scientific contributions of Professor Constantin Corduneanu, an outstanding researcher in stability and control theory, and oscillations.

MSC: 01-01; 01-02

\section{Corduneanu's life}

Constantin Corduneanu was born on July 26, 1928, in the city of Iaşi, Province of Moldova, Romania, from the parents Costache and Aglaia Corduneanu. He completed his elementary education in the village of Potangeni, Movileni commune in the District of Iaşi, located at a distance of about $25 \mathrm{Km}$. from the City of Iaşi, where his parents and some uncles were his teachers. This village was also the place where his paternal grandparents were living. At the age of 12, he had to go to the City of Iaşi to get his secondary education. He did not want to take the advice of his parents or his grandfather. Instead, he chose the idea of one of his uncles, who, during the First World War, was a sergeant in the Romanian Cavalry. He participated in the competition for a place at the Military Lyceum of Iaşi, placing 10th out of 400 competitors. He completed his secondary education in 1947. Corduneanu had great mathematics teachers during his secondary education. For example, Nicolae Donciu, who was serving as an assistant to Dimitrie Pompeiu, well known in complex analysis at the time. These teachers encouraged and supported him to participate in the activities at Gazeta Matematica, including participation at the competitions organized yearly by this publication and its supporters. He received the fifth prize in 1946 and first prize in 1947.

These teachers and his growing interest and knowledge in mathematics convinced him to dedicate his career to this discipline. In the fall of 1947, Corduneanu became a student at the Alexandru Ioan Cuza University (AICU) in Iaşi (today known as the University of Iaşi), taking mathematics as the subject of his studies. He obtained his Ph.D. in mathematics from AICU in 1956 under the supervision of Professor Ilie Popa; his dissertation titled "global problems for first and second-order nonlinear ordinary differential equations." From 1947 until 1977, Corduneanu was a student, teaching assistant, assistant, lecturer, Associate Professor, Professor, Dean, and Vice-Rector for research and graduate studies at AICU in Iaşi. He also had some research positions with the Mathematical Institute of the Romanian Academy and served the Iaşi Polytechnic Institute occasionally. In addition, he served the newly created institution, which is known today as the University of Suceava (Stefan cel Mare University) for three years. Corduneanu had very well educated professors, with Ph.D. degrees or postdoctoral periods in Romania, Italy, France, and Germany. The courses he took covered a vast area of mathematics at the level achieved by this science before the Second World War (WW2). They included abstract algebra, real analysis, differential geometry (classic and Riemann spaces), mechanics, complex variables, and many special topics (Fourier series, relativity, minimal surfaces, number theory, probability theory).

*Corresponding Author: Mehran Mahdavi: Department of Mathematics, Bowie State University, 14000 Jericho Park Road, Bowie, Maryland 20715, U.S.A. E-mail: mmahdavi@bowiestate.edu 
A final year course on topological groups (following Pontrjagin's book - the English edition) prompted him to write his thesis, required for obtaining the Diploma of Licentiate in Mathematics (something between a Bachelor's and a Master's degree), on "the group of automorphisms of a topological group." He defined a topology on the group of automorphisms in the case of a bounded topological group (i.e., all Markov's seminorms are bounded on this topological group); his first results published were part of his thesis in 1950. In 1951, when preparing his thesis for the degree of Licentiate, he discovered an error in a paper published in Portugaliae Mathematica due to the University of California Los Angeles Professor Szetsen Hu. The error could not be repaired under accepted hypotheses. In 1953, Corduneanu changed his field of research to differential and related equations. Corduneanu's research activities began sixty-eight years ago.

During the period 1948-1956, due to the changes brought by the new regime in Romania, the Romanian connections with the Western World were abolished. They did not get publications coming from the Western World, the student exchanges that were common until the WW2 were suspended, and a period of isolation began. Fortunately, under the new circumstances, for mathematicians, the flourishing of the domain had continued because the material received from the former Soviet Union, regarding mathematical research as well as teaching, were of the highest quality. Corduneanu used in his training as mathematician books or other publications authored by such professors as I. G. Petrovski, I. V. Smirnov, A. N. Kolmogorov, S. L. Sobolev, V. V. Stepanov and V. V. Niemytskii, A. N. Tychonoff and others of the same caliber. The first mathematical book he studied in entirety was Pontrjagin's famous book on Topological Groups (1949-1950). Corduneanu even had access to publications authored by Western mathematicians, which were translated to Russian. He could read books on differential equations by G. Sasone, Lamberto Cesari, E. A. Coddington and N. Levinson, E. Kamke, and others.

In 1957, he organized, with the help of his colleagues at AICU, a seminar on "Qualitative Theory of Differential Equations.” In 1961, he participated at the Congress of the International Union of Mechanical Sciences, organized by Iurii Mitroploskii in Kiev. In that meeting, he met for the first time several well-known mathematicians from various countries; Solomon Lefschetz, Jack Hale, and L. Cesari, all from the United States of America (the US), and V. V. Niemytskii from the U.S.S.R.

In 1977, Corduneanu decided to expatriate from Romania, and reside in the US. He went to Italy and taught some courses at the International Center for Theoretical Physics (UNESCO) in Trieste, but the Romanian authorities only allowed him to travel to Italy. In January 1978, Corduneanu moved to the US and had a teaching position at the University of Rhode Island. He was a visiting professor there in 1967-1968 and 1973-1974 academic years; hence familiar with the place and colleagues. In the academic year 1978-1979, he was a visiting professor at the University of Tennessee at Knoxville. Corduneanu obtained a tenured position as a Professor in the fall of 1979 at the University of Texas at Arlington (UTA). V. Lakshmikantham was the Chair of the mathematics department at the UTA. He brought Corduneanu to strengthen the mathematics doctoral program. At UTA, Corduneanu made significant contributions to the rise of the department's doctoral program, which had been created in 1974. By 1987, the American Mathematical Society ranked UTA's Department of Mathematics 89th out of 620 mathematics doctoral-granting institutions in the US.

I had the opportunity to meet Corduneanu for the first time in my life at the International Conference on Theory and Applications of Differential Equations held in Columbus, Ohio, in March 1988. Reza Aftabizadeh from Ohio University, a former student of Corduneanu, organized this conference, and I was his assistant. I had already taken two semesters of differential equations with Aftabizadeh, and he used Corduneanu's book, Principles of Differential and Integral Equations for the first semester. In that meeting, I asked Corduneanu to be my doctoral advisor and after I told him that I had taken all the required courses like Real Analysis, Differential Equations, etc., he agreed. I transferred to the UTA in 1988. I did not know anybody there. Corduneanu and his wife, Ms. Alice, deceased in 2005, gave me a room in their house until I found an apartment after two weeks. Every year the Corduneanus invited me to their house for Thanksgiving and Christmas and treated me as if I were their son. They did not have children. I never forget their kindness and generosity.

Upon my arrival, Corduneanu gave me the manuscript of his book Integral Equations and Applications and asked me to read it. My Ph.D. dissertation was based on the materials of this book, which was published by the Cambridge University Press in 1991. Corduneanu organized a research seminar during the period September 1990 to May 1994, in the department. All of his students and faculty members attended the 
seminar, and students presented their research work. Visitors occasionally participated and presented their research results, including V. Barbu, Y. Hamaya, M. Kwapisz, I. Gyori, and Cz. Olech.

Corduneanu was well-liked and respected by all faculty members in the department. They called him affectionately C. Corduneanu always assisted everybody, including students, faculty members, and mathematicians he met for the first time. He was intellectually generous to all. Late Professor Bernfeld, whose specialty was also differential equations, always said that he was so amazed by Corduneanu's vastness of knowledge in differential equations. He mentioned that anytime he asked Corduneanu a question, Corduneanu sent him to a specific paper in a particular journal that would provide the answer to his question.

Corduneanu taught numerous courses, and his classes were always fully attended, including many engineering students. He was very popular and respected among students, and they all wanted to take his classes. Doctoral students wanted to have Corduneanu as a member of their oral comprehensive examinations committee or as a member of their dissertation defense committee because he genuinely wished that students would succeed in their academic endeavors. Corduneanu did his utmost to help the students answering their questions, guiding them, and advising them on what books or papers to read.

In May 1990, Corduneanu, along with faculty members from the engineering department, organized the Integral Methods in Science \& Engineering conference at the UTA. In May 1996, Corduneanu, along with several faculty members, including faculty from engineering, organized the Volterra Centennial Symposium at the UTA. About 100 mathematicians and engineers from 15 countries attended the conference and presented their results. In January 2000, Corduneanu and I organized a special session on Integral Equations and Applications for the American Mathematical Society at the Joint Mathematics Meetings in Washington, D. C. We invited 25 mathematicians from various countries and the US to present talks. Corduneanu retired in September 1996, after 47 years in higher education in Romania and the US, holding the title of Emeritus Professor of Mathematics. Corduneanu was very active after his retirement. He published three research monographs and attended numerous conferences and meetings in the US and around the world.

The Russian School influenced most of Corduneanu's research in differential equations and related fields, given the abundance of publications in Russian largely available to him during the years of his formation as a researcher, as well as the long tradition of excellence established by Liapunov, Chetayev, and Persidskii. He made constant use of the literature in Russian concerning differential equations and their applications.

In the next few paragraphs, Corduneanu's encounters and connections with his Russian colleagues are presented more or less in chronological order, sometimes just casual encounters with I. G. Petrovski, N. K. Bary, B. Gnedenko, A. P. Norden, and N. Efimov, or with mathematical interest with M. A. Krasnoselskii, V. A. Pliss, N. N. Krasovskii, N. V. Azbelev, V. M. Aleksejev, V. V. Rumiantsev, and V. V. Niemytskii.

Corduneanu had mathematical interactions with V. V. Niemytskii, whom he met several times in Moscow and Kiev, starting in 1961. They had been in correspondence. Niemytskii was the editor of Referativnyi Zhurnal and knew about Corduneanu's research from that journal. They had fruitful (for him) discussion, and when Niemytskii asked him about his current study, he answered in Russian "Ja vrashchayu vokrug nepodvizhnoi tochki." That was the method he was using for obtaining global existence of solutions and studying the existence of almost periodic or just bounded solutions to nonlinear differential equations (ordinary differential equations, sometimes partial differential equations). Corduneanu was applying Banach, Schauder and Tychonoff fixed point theorems to obtain those results. Niemytskii visited AICU for at least one week and gave two or three lectures, participated in a seminar meeting, and interacted with some of the faculty there. Corduneanu had more opportunities to talk to him because he accompanied Niemytskii in a two-day excursion in the Carpathian Mountains. Moreover, before he had met him, he translated to Romanian Niemytskii's book Topological Methods in the Theory of Integral Equations.

In the early 1960s, Corduneanu decided to shift his interest from ordinary differential equations or delay equations to integral equations. This shift was mainly due to his encounter with Krasnoselskii after reading his book. Professor V. V. Rumiantsev had known about Corduneanu's work on comparison method and partial stability, and guided Laszlo Hatvani, from the University of Szeged, to write his dissertation at Moscow University, based on that research (1975). Rumiantsev visited the UTA on the occasion of an International Conference on Differential Equations organized by the school. 
Professor V. A. Pliss from Sankt-Petersburg studied the boundedness problem of solutions of ordinary differential equations and included Corduneanu's results in a book he published in 1964. The book was later translated into English. Corduneanu met Professor V. M. Aleksejev at the International Congress of Mathematicians in Moscow in August 1966. Before, they had met in publications. Aleksejev cited Corduneanu's work regarding the comparison method in his papers. Corduneanu used Aleksejev's book on control theory when teaching his graduate students at the UTA.

Professor N. V. Azbelev had founded a school dealing with functional equations, in Perm, Russia. Azbelev visited the UTA in 1996. Corduneanu was in communication with some of Azbelev's former students and collaborators who were spread around the world in various countries. Azbelev and Corduneanu had somewhat different approaches to the study of functional differential equations, but complementary to each other.

Professor N. N. Krasovskii and Corduneanu met in Athens (Greece) in 1966, and in Moscow in 1992. Corduneanu was aware of Krasovkii's work and had read and used his results since 1956. In 1956, Professors Krasovskii and Germaidze published a paper on the stability of general ordinary differential equations, with respect to perturbations bounded in the mean. The underlying assumption on the ordinary differential equation system was its uniform asymptotic stability. In January 1957, at a session of the Romanian Academy, Corduneanu presented a similar paper, without having seen before the article of Krasovskii-Germaidze. His underlying assumption was the exponential asymptotic stability of the zero solution of the nonlinear system (unperturbed). The way he had measured the perturbation was the same that the Krasovskii-Germaidze paper was using. However, at that time, he did not know that the integral norm he was using is equivalent to the supremum norm used by Krasovski-Germaidze. One year later, Corduneanu found the equivalence of the norms in papers by Massera and Schaffer. The result established by Krasovskii-Germaidze was better, because of the weaker assumption on the unperturbed system. In 1960, Corduneanu used his comparison method that he developed and proved more results on the preservation of stability under perturbations, including nonlinear perturbations and the result of Krasovskii-Germaidze.

\section{Corduneanu's Research Work}

\section{Global Problems in the Theory of Ordinary Differential Equations}

These types of problems kept Corduneanu's attention at the beginning of his career. His doctoral thesis, which he defended in 1956 at the University of Iaşi, contained problems of that type. Professors Miron Nicolescu, then president of the Romanian Academy, Grigore Moisil, and Nicolae Teodorescu from Bucharest, a former student of J. Hadamard at Sorbonne were members of his thesis defense committee. Corduneanu continued research work in this field for several years, studying global existence, stability problems, oscillation theory, with particular regard to the almost periodic behavior of solutions to various classes of nonlinear equations.

\section{Qualitative Theory of Differential Equations, with Special Regard to Stability Theory}

His work in this category was mainly directed to ordinary differential equations and equations with causal operators. Corduneanu published his seminal paper in Russian in 1960 titled "Method Differential Neravenstv v teorii Ustoichivosti." In that paper, he made one of the first steps in applying the so-called Comparison Method and proving in a single theorem all basic results on Liapunov stability, based on using the Chaplyguine - Wazewski approach to differential inequalities, and the Liapunov's function in general form simultaneously. This method had been widely applied by the School of Academician V. M. Matrosov, Russia; and in Ukraine by Academician A. A. Martynyuk and his followers. The result Corduneanu published in 1960, was included in several monographs and treatises, by authors like V. Lakshmikantham and S. Leela, W. Hahn, T. Yoshizawa, A. Halanay, G. Sansone and R. Conti and others. 


\section{Theory of Integral Equations}

In this domain, Corduneanu contributed to generalizing the method due to Massera and Schaffer, from differential equations to integral equations. His book Integral Equations and Applications published by Cambridge University Press in 1991 contains the basic results he had obtained until 1987. This book became one of the most often quoted references in the literature. In this book, Corduneanu illustrated that integral equations constitute a very useful and successful tool in contemporary research, unifying many particular results available for other classes of functional equations (differential, integrodifferential, delayed argument). Also, his book Integral Equations and Stability of Feedback Systems published by Academic Press in 1973 contains qualitative results with applications to the stability of systems of automatic control.

\section{Equations with Causal Operators}

Corduneanu aimed to present, as much as possible, a unified theory of equations with causal operators (according to Volterra - Tonelli - Tychonoff), that can cover the classical types of ordinary differential equations, equations with delay, integrodifferential equations with Volterra type integral, and some discrete evolution equations. The book Functional Equations with Causal Operators published by Taylor \& Francis in 2002 contains these topics. This book covers research conducted by Corduneanu and a group of his students as well as joint projects with Mehran Mahdavi and Yizeng Li. The book by Corduneanu, Li, and Mahdavi titled, "Functional Differential Equations: Advances and Applications," published by Wiley in 2016, also is dedicated to this type of equations and their connection with the classical kinds of equations.

\section{Fourier Analysis (Generalized)}

For over half a century, a wide range of problems has been investigated in this field. Corduneanu made significant contributions to the oscillation theory and oscillation theory with particular regard to the almost periodic behavior of solutions to various classes of nonlinear equations. His books Almost Periodic Oscillations and Waves published by Springer in 2009, and Almost Periodic Functions published by John Wiley in 1968 are concerned with this subject.

Corduneanu presented over 140 papers at various meetings and conferences on mathematical topics, held in Romania, Hungary, Czechoslovakia, Bulgaria, Soviet Union, Russia, Ukraine, Germany, Belgium, Italy, The US, The Netherlands, England, Scotland, Japan, Canada, France, Morocco, Greece, Poland, China, Portugal, and Chile. He was invited to present his research work at over 31 national and international conferences. He was an invited lecturer at 53 Colloquium and Exchange Programs in various countries outside of the US. From 1968 till 2017, he was an invited lecturer at 36 universities in the US. Corduneanu was the founding editor of the journal Libertas Mathematica, a publication of the American Romanian Academy of Arts and Sciences. He published the first volume in 1981 and continued this task until 2011. From 1990 to 1994, Li and I assisted him in the publication of this journal. We were doing most of the preparation of the journal, copying pages, pagination, collating, and organizing; we submitted the last stage of the work to a publishing shop for binding the journal. After long hours of work on Fridays, Saturdays, and Sundays, Corduneanu would take us to Cici's Pizza, a pizza joint close to campus that had a buffet, and we had lunch or dinner there.

Corduneanu attended more than 100 national and international conferences, had short visits and gave talks about his research work in over 60 universities or institutes, in over 20 countries including Russia, Ukraine, Germany, England, France, Italy, China, Japan, Hungary, Poland, Portugal, and Chile. Authors around the world have quoted Corduneanu's work in over 110 books, monographs, and textbooks. 


\title{
Teaching Activities
}

$\begin{array}{ll}\text { Aug 1996-2018 } & \text { Emeritus Professor, University of Texas at Arlington; } \\ \text { 1979-1996 } & \text { Professor, University of Texas at Arlington; } \\ 1978-1979 & \text { Visiting Professor, University of Tennessee; } \\ \text { Spring 1978 } & \text { Visiting Professor, University of Rhode Island; } \\ 1968-1977 & \text { Professor, University of Iaşi; } \\ 1973-1974 & \text { Visiting Professor, University of Rhode Island; } \\ 1967-1968 & \text { Visiting Professor, University of Rhode Island; } \\ 1962-1967 & \text { Associate Professor, University of Iaşi; } \\ 1955-1962 & \text { Lecturer, University of Iaşi; } \\ 1950-1955 & \text { Assistant, University of Iaşi; } \\ 1949-1950 & \text { Teaching Assistant, University of Iaşi. }\end{array}$

\section{Administrative}

1998-2018 Emeritus President, American Romanian Academy of Arts and Sciences;

1995-1998 President, American Romanian Academy of Arts and Sciences;

1982-1995 Counselor and member of the Executive Committee, American Romanian Academy of Arts and Sciences;

1972-1977 Vice-Rector, University of Iaşi, 1972-1977 (on leave, 1973-1974). In charge of research and graduate studies;

1968-1972 Dean of the Mathematics Faculty, University of Iaşi;

1966-1967 Rector (President) of the Teachers Training College in Suceava (today the Stefan cel Mare University, Suceava);

1964-1967 Head (Chairman) of the Mathematical Division at the Teachers Training College in Suceava.

\section{Editorial Activities}

\section{Editor:}

1981-2011 Libertas Mathematica, the Mathematical Journal of the American Romanian Academy of Arts and Sciences.

\author{
Associate Editor: \\ 2001-2018 Nonlinear Dynamics and Systems Theory (Kiev, Ukraine); \\ 2001-2018 Nonlinear Functional Analysis and Applications (Korea); \\ 1996-2018 Annals of Ovidius University (Constantza, Romania); \\ 1996-2018 Analele Stiintifice University Iaşi (Romania); \\ 1995-2018 Functional Differential Equations (Israel); \\ 1994-2018 Communications on Applied Nonlinear Analysis (U. S. A.); \\ 1979-1995 Journal of Integral Equations and Applications (U. S. A.); \\ 1988-1992 Differential and Integral Equations (U. S. A.); \\ 1977-1985 Nonlinear Analysis: Theory, Methods and Applications (U. K.); \\ 1973-1978 Revue Roumaine de Math. Pures Appl. (Romania); \\ 1969-1977 Analele Stiintifice University Iaşi (Romania); \\ 1967-1975 Mathematical Systems Theory (Germany).
}




\section{Awards}

2010 Honorary Doctor, University of Ekaterinburg, Russia;

2005 Honorary member of the Mathematical Institute of the Romanian Academy, Bucharest;

2003 Doctor Honorius Causa, Stefan cel Mare University, Suceava, Romania;

2003 Best paper award, CASYS’03, Liege, Belgium;

2002 "V. Pogor" Prize of the Municipality of Iaşi;

2001 Medal of Merit in Mathematics from the Union of Czech Mathematicians;

1999 Doctor Honorius Causa, Transylvania University, Brasov, Romania;

1994 Doctor Honorius Causa, University of Iaşi, Romania;

1994 Doctor Honorius Causa, Ovidius University, Constantza, Romania;

1991 Distinguished Research Award, University of Texas at Arlington, U. S. A.;

1974 Elected Correspondent Member of the Romanian Academy of Sciences in Bucharest, Division of Mathematical Sciences;

1963 The Research Award of the Romanian Academy of Sciences, for research work in "Stability Theory of Automatic Control Systems;"

1961 The Research Award of the Department of Education in Bucharest, for research conducted in regard to "Comparison Method in Stability Theory."

\section{Invited Lectures (Colloquium Programs, Exchange Programs)}

1. Czechoslovakia: The Mathematical Institutes of the Academies of Sciences and the Universities in Prague, Brunno, and Bratislava $(1962,1966,1971)$.

2. Belgium: The University of Louvain $(1971,1976)$.

3. United Kingdom: The Universities of Warwick, Durham, and Sussex $(1971,1973)$; The University of Wales (1989); The University of Dundee (1992); University of Strathclyde (1994).

4. Canada: The University of Montreal (1973); McGill University (1987); Montreal Polytechnic (1989); University of Victoria (1993); University of Waterloo (1994).

5. Italy: The Universities in Milano, Florence, Perugia, Naples, and Politecnico in Torino (1965 - 1993); Instituto di Alta Mathematica in Rome (1971).

6. Morocco: The University of Marrakech $(1994,1995)$.

7. Japan: Okayama University of Science, Okayama; Gunma University, Kiryu; Shizuoka University, Hamamatsu (2004); the University of Electro-Communications, Chofu (2001).

8. West Germany: Free University of Berlin (2001); Technical University in Aachen (1986).

9. Chile: The University of Osorno (2002).

10. China: Tianjin University (1998); Normal University, Beijing; Harbin University, Harbin (2009).

11. U.S.A.: Arizona State, Brown, Case Western Reserve, Cornell, Drexel, Florida State, Southern Methodist, Texas Christian, and Wichita State Universities; the Universities of Rhode Island, Florida at Gainesville, Georgia at Athens, Colorado at Boulder, Colorado at Colorado Springs, Tennessee at Knoxville, Maryland at College Park, South Florida, Arizona at Tucson, Southern California, Wisconsin at Madison, Texas at Arlington, Dallas at Irving, New Mexico at Albuquerque, California at Los Angeles, Utah at Salt Lake City, Miami at Coral Gables; Bishop College in Dallas, Pomona Colleges, Rensselaer Polytechnic Institute, Georgia Institute of Technology, Virginia Polytechnic Institute and State University; Ohio University, University of Pittsburgh, University of Houston (Downtown); Virginia State University, Petersburg; Howard University, Washington, D. C. (1968 - 2017). 


\section{Memberships}

American Mathematical Society, Society for Industrial and Applied Mathematics, Mathematical Association of America, American Romanian Academy of Arts and Sciences, Romanian Academy, Honor Society for International Scholars, PHI BETA DELTA, International Federation of Nonlinear Analysts.

Corduneanu guided and assisted the research work of the following students: Viorel Barbu, Marica Lewin, C. P. Tsokos, A. N. V. Rao, S. Travis, D-Ph. K. Hsing, Reza Aftabizadeh, and William J. Layton.

Corduneanu was the Ph.D. advisor of the following students:

Nicolai Pavel (Ph.D., 1972, University of Iaşi), Sergiu Aizicovici (Ph.D., 1977, University of Iaşi), Hushang Poorkarimi (Ph.D., 1984, UTA), Mohammad Hadi Moadab (Ph.D., 1988, UTA), Ali Ansari (Ph.D. 1990, UTA), Mehran Mahdavi (Ph.D., 1992, UTA), Yizeng Li (Ph.D., 1993, UTA), and Zephirinus Okonkwo (Ph.D., 1994, UTA).

In 2017 Corduneanu fell ill. He was in and out of nursing facilities and hospitals frequently. However, he continued his schedule of traveling to conferences and meetings. He visited Romania several times. In August 2018, he attended a conference that was held in honor of his 90th birthday, at Ural State University in Ekaterinburg, Russia. On December 10, 2018, I received a phone call from a Corduneanu's friend who was taking care of him at his home in Arlington, Texas, that he was very ill and about to pass away. He was taken to the Intensive Care Unit at a hospital in Arlington. On December 14, I flew to Arlington and stayed there until December 20, visiting Corduneanu every day at the hospital. On December 27, I received a text message from Corduneanu's friend that he had passed away the night before, December 26, at 10:30 pm. I was so saddened, and my heart ached. I have known Constantin Corduneanu for 30 years. He was an exemplary mathematician and, more importantly, a decent, kind, generous, and honorable man. Corduneanu did not have any children and was preceded in death by his wife, Alice, in 2005. Corduneanu's body was taken to Iaşi, and he was buried there, next to his wife, Alice.

\section{List of Books and Monographs by C. Corduneanu}

1. Functii Aproape Periodice, Editura Academiei, Bucharest, 1961.

2. Almost Periodic Functions, John Wiley \& Sons, New York, 1968 (translation of no. 1 above, enlarged: with the cooperation of N. Gheorghiu and V. Barbu).

3. Principles of Differential and Integral Equations, Allyn \& Bacon, Inc., Boston, 1971.

4. Differential and Integral Equations (Romanian), University of Iaşi Press, 1971 (Romanian version of no. 3).

5. Integral Equations and Stability of Feedback Systems, Academic Press, Inc., New York, 1973.

6. Differential and Integral Equations (Romanian), University of Iaşi Press, 1977 (with an Appendix by N. Pavel).

7. Principles of Differential and Integral Equations, Chelsea Publishing Company, The Bronx, New York, 1977.

8. Principles of Differential and Integral Equations (Stereotype edition of no. 7) (this edition is currently distributed by the American Mathematical Society and Oxford University Press).

9. Almost Periodic Functions (second English edition, enlarged), Chelsea Publishing Company, The Bronx, New York, 1989 (this edition is currently distributed by the American Mathematical Society and Oxford University Press).

10. Integral Equations and Applications, Cambridge University Press, 1991.

11. Functional Equations with Causal Operators, Taylor and Francis, London, 2002. 
12. Integral Equations and Applications (a paperback edition), Cambridge University Press, 2008.

13. Almost Periodic Oscillations and Waves, Springer, New York, 2009.

14. Integral Equations and Applications (a paperback edition), Cambridge University Press, New Delhi, India, 2014.

15. Functional Differential Equations: Advances and Applications, John Wiley \& Sons, Hoboken, New Jersey, 2016 (with Yizeng Li and Mehran Mahdavi).

\section{List of C. Corduneanu's Selected Papers}

1. Approximation and stability of solutions of hyperbolic equations with characteristic data, Comm. Acad. R. P. R. V, 21-26, 1955. (Romanian)

2. On a boundary value problem for second order nonlinear differential equations, Analele Stiintifice University Iaşi, N. S. 1, 11-16, 1955. (Romanian)

3. Differential systems with bounded solutions, Comptes Rendus Acad. Sci., Paris 245, 21-24, 1957. (French)

4. Differential equations in Banach spaces: Theorems of existence and continuability, Rendiconti Accad. Naz. Lincei XXIII, 226-230, 1957. (Italian)

5. On the existence of bounded solutions for nonlinear differential systems, Annales Polonici Math., $\mathbf{V}$, 103-106, 1958. (French)

6. On conditional stability under constantly acting disturbances, Acta Scientiarum Math. Szeged XIX, 229237, 1958. (French)

7. On boundary value problems for differential systems, Rendiconti Mat. Napoli, XXV, 98-106, 1958. (Italian)

8. On asymptotic stability I, Analele Stiintifice University Iaşi, V, 37-40, 1959. (French)

9. On asymptotic stability II, Revue Roumaine Math., V, 209-213, 1960. (French)

10. On the existence of bounded solutions to some classes of nonlinear differential systems, Doklady Akad. Nauk SSSR, 131, 735-737, 1960. (Russian)

11. Application of differential inequalities to stability theory, Analele Stiintifice University Iaşi, VI, 47-58, 1960. (Russian)

12. On some nonlinear differential systems, Ibidem, 257-260. (French)

13. Global existence theorems for differential systems with delayed argument, Studii Cercetari Mat. Iaşi, XII, 249-258, 1961. (Romanian) (Russian version in the Proceedings of ICNO Symp. Kiev, 1961)

14. An integral equation from the theory of automatic control, Comptes Rendus Acad. Sci. Paris 256, 35643567, 1963. (French)

15. On partial stability, Revue Roumaine Math., IX, 229-236, 1964. (French)

16. Some problems concerning stability theory, Abhandl. Deutsch. Akad. Wissensch. zu Berlin (Math-Physik Klasse) (1), 143-156, 1965. (French)

17. Global problems in the theory of Volterra integral equations, Annali Mat. Pura Appl., 67, 349-363, 1965. (French)

18. On certain Volterra functional equations, Funk Ekvacioj, 9, 119-127, 1966. (French)

19. Some qualitative problems in the theory of integro-differential equations, Colloquium Mathematicum, 18, 77-87, 1967. (French)

20. Some perturbation problems in the theory of integral equations, Mathematical Systems Theory I, 143-153, 1967.

21. Stability of linear time-varying systems, Math. Systems Theory, 3, 151-155, 1969.

22. Periodic and almost periodic solutions of some convolution equations, Trudy Fifth Int. Conf. Nonlinear Osc., Kiev III, 311-320, 1970.

23. Some problems concerning partial stability ( ${ }^{\star}$ ) , In Symp. Math., 6, 141-154, Academic Press, 1971.

24. Stability problems for some classes of feedback systems, In the volume "Eq. Diff. Fonct. non lineaires", Herman, Paris, 398-405, 1973. 
25. On partial stability for delay systems, Annales Polonici Math., XXIX, 357-362, 1974-1975.

26. Functional equations with infinite delay, Bolletino Unione Mat. Italiana 11 (suppl.), 173-181, 1975.

27. The stability of some feedback systems with delay, J. Math. An. Appl., 51, 377-393, 1975. (with N. Luca)

28. Equations with unbounded delay: A survey, Nonlinear Analysis, TMA, 4, 831-877, 1980. (with V. Lakshmikantham)

29. Bounded and almost periodic solutions of certain nonlinear elliptic equations, Tohoku Math. J., 32, 265278, 1980.

30. Recent contributions to the theory of differential systems with infinite delay, Libertas Mathematica, I, 91-116, 1981.

31. Almost periodic discrete processes, Libertas Mathematica, II, 159-169, 1982.

32. Bielecki's method in the theory of integral equations, Annales Univ. Mariae-Curie Skladowska, Lublin, 38 (2), 23-40, 1984.

33. Two qualitative inequalities, J. Differential Equations, 61, 16-25, 1985.

34. A singular perturbation approach to abstract Volterra equations, In Nonlinear Analysis and Applications, M. Dekker, 133-138, 1987.

35. Perturbation of linear abstract Volterra equations, J. Integral Equations and Appl., 2, 393-401, 1990.

36. LQ-Optimal control problems for systems with abstract Volterra operators, Tekhn. Kibernetika (1), 132136, 1993. (Russian)(English version in Libertas Mathematica)

37. Discrete qualitative inequalities and applications, Nonlinear Analysis, TMA, 25, 933-939, 1995.

38. Asymptotic behavior of systems with abstract Volterra operators. In (C. Corduneanu , Editor) Qualitative Problems for Differential Equations and Control Theory, World Scientific, Singapore, 113-120, 1995. (with M. Mahdavi)

39. Neutral functional differential equations with abstract Volterra operators. In Advances in Nonlinear Dynamics, 5, Gordon \& Breach, 229-235, 1997.

40. On neutral functional differential equations with causal operators, Proceedings of the Third Workshop of the Inter. Inst. General Systems Science: Systems Science and Its Applications, Tianjin People's Publishing House, Tianjin, 43-48, 1998. (with M. Mahdavi)

41. Abstract Volterra equations: A survy, Mathematical and Computer Modelling, 32 (11), 1503-1528, 2000.

42. Existence of solutions for neutral functional differential equations with causal operators, Journal of Differential Equations, 168, 93-101, 2000.

43. On neutral functional differential equations with causal operators, II. Integral Methods in Science and Engineering, Chapman \& Hall/CRC, London, 102-106, 2000. (with M. Mahdavi)

44. Discrete dynamical systems described by neutral equations. In Differential Equations and Nonlinear Mechanics (K. Vajravelu, Editor), 69-74, Kluwer Academic, Dordrecht, 2001.

45. Some existence results for functional equations with causal operators, Nonlinear Analysis, TMA, 47, 709716, 2001.

46. Absolute stability for neutral differential equations, European Journal of Control, 209-212, 2002.

47. Neutral functional equations in discrete time. In Proceedings of the Inter. Conf. on Nonlinear Operators, Differential Equations and Applications, Babes-Bolyai Univ. of Cluj-Napoca, Romania, III, Cluj-Napoca, Romania, 33-40, 2002. (with M. Mahdavi)

48. A class of second order functional differential equations of neutral type, Mathematical Reports, Romanian Academy, 5 (55) (4), 293-299, 2003. (with M. Mahdavi)

49. On exponential asymptotic stability for functional differential equations with causal operators. In Advances in Stability Theory at the end of 20th Century (A. A. Martynyuk, Editor), 15-23, Taylor \& Francis, London, 2003. (with Y. Li)

50. A modified LQ-Optimal control problem for causal functional differential equations, Nonlinear Dynamics and Systems Theory, 4, 139-144, 2004.

51. Some remarks on functional equations with advanced-delayed operators. In American Institute of Physics Conf. Proceedings, 718, Liege, Belgium, 204-209, 2004.

52. Second order functional equations of neutral type, Dynamic Systems and Applications, 14, 83-89, 2005. 
53. Stability of invariant sets of functional differential equations with delay, Nonlinear Functional Analysis and Applications, 10, 11-24, 2005. (with A. O. Ignatyev)

54. A duality principle in the theory of dynamical systems, Nonlinear Dynamics and Systems Theory, 5, 135140, 2005. (with Y. Li)

55. Some function spaces on R, Libertas Mathematica, XXVI, 79-82, 2006. (with M. Mahdavi)

56. New examples for a duality principle in the theory of dynamical systems. In Proceedings of CASYS'05, American Institute of Physics, 839, Liege, Belgium, 340-343, 2006. (with Y. Li and M. Mahdavi)

57. Almost periodicity in functional equations. In: Progress in Nonlinear Differential Equations and Their Applications (V. Staicu, Editor), 75, Birkhauser, 157-163, 2007.

58. Neutral functional equations with causal operators on a semi-axis, Nonlinear Dynamics and Systems Theory, 8, 339-348, 2008. (with M. Mahdavi)

59. Neutral functional equations of the second order, Functional Differential Equations, 16, 263-271, 2009. (with M. Mahdavi)

60. Some classes of second order functional differential equations, Nonlinear Analysis TMA, 71, e865-e871, 2009.

61. Some comments on almost periodicity and related topics, Communications in Mathematical Analysis, 8 , 5-15, 2010.

62. Almost periodicity in semilinear systems. In Integral Methods in Science and Engineering (C. Constanda and P. J. Harris, Editors), Birkhauser, Boston, 141-146, 2011.

63. Boundedness of solutions for a second order differential equation with causal operators, Nonlinear Studies, 18, 135-139, 2011.

64. A scale of almost periodic function spaces, Differential and Integral Equations, 24, 1-27, 2011.

65. A neutral-convolution type functional equation, Libertas Mathematica, 31, 87-92, 2011 (with Y. Li)

66. $A P_{r}$-almost periodic solutions to functional differential equations with deviated argument, Functional Differential Equations, 19, 59-69, 2012.

67. Elements of an axiomatic construction of the theory of almost periodic functions, Libertas Mathematica, 32, 5-18, 2012. (French)

68. Almost periodicity: a new approach. In VII-th International Congress of Romanian Mathematicians/Editura Academiei, 121-129, Bucharest, 2013.

69. Formal trigonometric series, almost periodicity and oscillatory functions, Nonlinear Dynamics and Systems Theory, 13, 367-388, 2013.

70. Existence of $A P_{r}$-almost periodic solutions for some classes of functional differential equations, African Diaspora Journal of Mathematics, 15, 47-55, 2013 (with M. Mahdavi)

71. Searching exponents for generalized trigonometric series, Nonlinear Dynamics and Systems Theory, 16, 298-319, 2016.

72. A glimpse on Fourier Analysis: Third Stage, International Journal of Numerical Analysis and Modeling, Institute for Scientific Computing and Information, 15, 520-523, 2018. 